\title{
UMA CARTOGRAFIA QUE PODE DANÇAR
}

\author{
A CARTOGRAPHY THAN CAN DANCE
}

UMA CARTOGRAFIA QUE PUEDE DANZAR

\author{
Valéria Cazetta \\ Ana Maria Hoepers Preve
}

\section{RESUMO}

Duas pesquisas em curso: "O que pode a cartografia e a geografia: investigações e invenções em educação" e "Geografias em corpos". Em ambas, a cartografia está em pauta. Por um lado, a cartografia como qualidade de acompanhar processos para que possamos dizer o que é preciso ser dito e, por outro, a cartografia da geografia, responsável por assegurar a produção de mapas ancorada na equivalência do espaço e sua representação. Do nosso encontro e do encontro das duas pesquisas elaboramos uma oficina na modalidade "Atividade Programada", oferecida para alunos do Programa de Pós-Graduação em Educação do Centro de Ciências Humanas e da Educação (FAED), da Universidade do Estado de Santa Catarina (UDESC). A fim de que nossas ideias de cartografia "falassem", cartografamos a sala de aula onde o encontro acontecia. Movimentamos, antes, as noções de cartografia em pauta para, em seguida, como numa dança, fazer com que os oficineiros deslocassem-nas, oscilando entre uma e outra. "O que pode a cartografia de uma sala de aula?". Assim, disparamos meios de expressão de uma ideia, criando espaçamentos, nos e por seus corpos, descolados de contextos figurativos e representacionais asfixiantes da ciência maior. Disponibilizamos ao grupo materiais diversos, prestando atenção aos processos de constituição daqueles mapas, afinal, o que é uma sala de aula? Quais são seus planos? Estavam em questão as dificuldades encontradas para o começo do mapeamento, não só do modo de trazer à tona as cartografias daquela sala de aula, mas do modo como presentificá-las.

PALAVRAS-CHAVE: Educação geográfica. Oficina. Cartografia geográfica. Cartografia guattariana/deleuziana.

\begin{abstract}
Two ongoing research: "What can cartography and geography do: research and inventions in education" and "Geographies in bodies". In both, cartography is at stake. On the one hand, cartography as a quality to go hand in hand with processes in order to allow us to say what is needed to be said; on the other, the cartography of geography that anchors the production of maps to the equivalence of space and its representation. As a result of our meeting and the meeting of two corpus of research we developed a workshop offered to Education Graduate students of Center of Humanities and Education (FAED) at the State University of Santa Catarina (UDESC). In order to make our ideas of cartography emerge we mapped the classroom where the meeting took place. We moved the cartography concepts in question, as in a dance, to promote students dislocate them, swinging between one and another. What can the cartography of a classroom do? Thus we put ourselves into action to provide means of expression of an idea, creating gaps in and through their bodies, detached from figurative and representational asphyxiating contexts of cartesian cartography. We provided various materials to them, paying attention to the maps'constitution, therefore, what is a classroom?; what are its plans? The difficulties encountered to begin mapping, not only the way of bringing out that classroom's cartography, but how to make them present began to appear.
\end{abstract}

KEYWORDS: Geographic education. Workshop. Geographic cartography. Guattarian/deleuzian cartography. 


\section{RESUMEN}

Dos investigaciones en curso tituladas “¿Qué puede la cartografía y la geografía: investigaciones y invenciones en educación?" y "Geografías en los cuerpos” atravesadas por la cartografía. Por un lado, la cartografía como cualidad de seguir procesos para que podamos decir lo que hay que decir y, por otro, la cartografía de la geografía, responsable de garantizar la producción de mapas anclados en la equivalencia del espacio y su representación. Como resultado de nuestro encuentro y del encuentro de las dos investigaciones se desarrolló un taller con alumnos del programa de pos-grado en Educación de la Universidade Estadual de Santa Catarina. Con la finalidad de promover el diálogo de nuestras ideas de cartografía procedimos a cartografiar el salón de clase donde se llevó a cabo el encuentro. Los conceptos de cartografía en movimiento para que, como en una danza, los participantes del taller las moviesen. “QQué es lo que puede la cartografía de una sala de clases?”, así nos pusimos en acción para proporcionar medios de expresión de una idea, creando espacios en sus y por sus cuerpos, desacoplados de los contextos de representación figurativa y asfixiante de la cartografía cartesiana. Proporcionamos al grupo diversos materiales, prestando particular atención a los procesos de constitución de los mapas, después de todo, ¿Qué es una sala de clases? ¿Cuáles son sus planes? Lo que se ponía en cuestión eran las dificultades encontradas para iniciar el mapeo, no sólo como una forma de evidenciar las cartografías de aquel salón de clases, sino en los modos de hacerlas presentes.

PALABRAS ClaVE: Educación geográfica. Taller. Cartografía geográfica. Cartografía guattariana/deleuziana.

\section{E AÍ, ESTENDENDO AS LINHAS PARA UM COMEÇO}

Como primeiro acorde para a dança, puxamos uma das linhas do poema Mapa de Wislawa Szymborska (2013):

Pontinhos pretos significam que ali vivem pessoas.

Valas comuns e súbitas ruínas

não cabem nesse quadro.

As fronteiras dos países mal são visíveis

como se hesitassem entre ser e não ser.

E o poema segue:

Gosto dos mapas porque mentem.

Porque não dão acesso à dura verdade.

Porque, generosos e bem-humorados, estendem-me na mesa um mundo que não é deste mundo.

A geógrafa inglesa Doreen Massey (2008, p.159) diz amar mapas: "eles nos transportam para longe, fazem com que sonhemos. No entanto, pode bem ter sido que, apesar disso, nossa noção de mapa tenha ajudado a apaziguar, a retirar a vida do modo como muitos de nós, mais comumente, pensamos o espaço". Continua a autora: "nem todas as visões do alto são problemáticas [...]. O problema aparece apenas se começamos a pensar que aquela distância vertical nos traz a verdade." (2008, p.160). 
Não se trata de propor argumentos contra ou a favor dos mapas, sejam eles de que natureza for, mas sim, de transtorná-los, dessasacralizando e desnaturalizando-os, porque "os pontinhos pretos significam/ que ali vivem pessoas. /Valas comuns e súbitas ruínas/ não cabem nesse quadro" (SZYMBORSKA, 2013), nos mapas, nas fotografias aéreas, nas imagens orbitais, nas enunciações textuais e visuais em geral. Essa dessacralização e desnaturalização dizem respeito ao modo como as visibilidades e as dizibilidades ${ }^{1}$ acerca do espaço são construídas culturalmente, porque todas as práticas discursivas e não-discursivas são práticas enunciadoras, portanto, produtoras de subjetividades. Faz-se necessário transtornar os mapas para dessacralizar e desnaturalizar aquela "impressão de que o espaço é uma superfície - que é a esfera de uma completa horizontalidade” (MASSEY, 2008, p.160), evidenciando, assim, os silenciamentos e apaziguamentos instituídos no interior de uma dada ordem discursiva da geografia escolar e da geografia acadêmica.

Inspiradas na ideia de transtornar os mapas e, por conseguinte, a cartografia, nosso intuito, neste texto, foi operacionalizar o mapa como conceito para fazer a cartografia “dançar". Dessa mirada, os mapas e a cartografia podem ser considerados como uma teia de aranha com suas linhas tramadas, conectando-nos aos fluxos que parecem não ter começo, apesar de nossos esforços para representá-los, congelá-los. Neste registro, a cartografia pode ser mais um campo de forças, uma máquina de guerra, do que propriamente um decalque. Os acontecimentos dão movência às suas linhas, embaralhando fronteiras e sugerindo percursos outros nos usos que se faz dos espaços territorializados e mapeados. Portanto, o mapa pode constituir-se como invenção, abrangendo poéticas (GIRARDI, 2014), e como criação de "espaçamentos que se cria no espaço, espaços lacunares, como maneira de estar no espaço, um novo pensar" (PREVE, 2010, p.16). O contato com essas linhas é de constituição frágil, pois não estamos falando de um programa de formação, mas de uma pequena experiência com linhas frágeis de uma educação como processo. Portanto, são os processos de pensar aquilo que não se move que interessa a uma movência do pensamento ante as forças das linhas dos mapas oficiais que prolongam as linhas cartesianas do pensamento. Isso pode produzir em nós um pouco de imaginação, a imaginação vitalmente necessária que a realidade do aprender escolar carece para fazer aflorar seus quinhões de virtual, o outro que todo espaço, todo corpo comporta. Cabe lembrar que, neste trabalho, o movimento de traçar linhas se deu, em sua maioria, com alguns professores atuantes em sala de aula e contou com outros profissionais ainda em processo de formação. Tentar, na cartografia da sala de aula, que as linhas cartesianas dos mapas oficiais experimentassem um devir louco como aquilo que toda linha cartesiana comporta. (PREVE, 2010). Por meio da escuta e das conversas presentes o tempo todo na oficina, conversas que acompanham o seu fazer, buscamos, neste texto, apresentar e analisar as forças que atravessaram a produção dos mapas da sala de aula, ou seja, as indicações que os mapas produzidos na oficina dão sobre a presença de uma cultura visual vinda pela cartografia escolar. Tais produções e suas conversas sobre o

\footnotetext{
${ }^{1}$ Na esteira de Michel Foucault (A arqueologia do Saber) e Gilles Deleuze (Foucault), Albuquerque Júnior (2011) afirmará que as visibilidades são maneiras de ver e de fazer ver, e as dizibilidades são modos de dizer e de fazer dizer.
} 
processo de composição apontaram possibilidades para que as linhas cartesianas da cartografia pudessem ser chacoalhadas, experimentando, como dito acima, um devir louco para o qual atribuímos a noção de dançar.

Ao mesmo tempo em que Preve (2010, p.16) afirma que "esses espaçamentos potencializam a geografia ao darem o tom intensivo a qualquer espaço", também adverte: "mas não é qualquer pensar que dá condição para o intensivo, mas todo pensar cuja força está em relação com outra força. Uma força não tem realidade em si". (p.16) Deleuze e Guattari (1995, p.30) afirmam: “o mapa é aberto, é conectável em todas as suas dimensões, desmontável, reversível, suscetível de receber modificações constantemente" porque não sabemos o que a vida nos revela, dada sua impermanência, e o que os corpos abrigam das vicissitudes dessa impermanência. Dar passagem às coisas que pedem passagem, que estão à margem, na iminência de esgotamento, criar espaçamentos - talvez seja essa condição aberta uma espécie de imperativo. Partir e voltar, parar e começar de novo para inventar mapas vitais que podem compor com os mapas oficiais cartografias de rasgadura, na acepção "de debater-se nas malhas que todo conhecimento impõe e de buscar dar ao gesto desse debate [...] uma espécie de valor intempestivo". (DIDI-HUBERMAN, 2013, p.185). É nesse sentido que não descolamos os mapas do próximo item dos processos que os originaram, isto é, de suas cartografias, porque esses mapas

\begin{abstract}
não são tomados como resultado de procedimentos cartográficos - como técnica de produção de mapas da cartografia científica -, mas como movimento no processo. São mapas na medida em que permitem apresentar o processo, mas deixam de sê-lo se se quiser utilizá-los como guia, orientador, indicador ou localizador; eles não levam a lugar nenhum, não servem para identificar quem os desenhou, tampouco para subsidiar diagnósticos de qualquer ordem, e, nesse sentido, eles querem, antes, confundir. (PREVE, 2010, p.18)
\end{abstract}

Desacostumar o silêncio dos papéis ou das plataformas virtuais, suportes dos mapas/imagens e textos, por meio da força de quem caminha pela estrada - para alguns craquelada, para outros somente uma linha reta, para outrem intensiva. Uma estrada intensiva, cujo caminhar solicita a invenção de outro jeito de estar nela, passar, pisar, ser atravessado por ela. Ora passos mais dilatados no tempo; ora passos apressados; ora passos ritmados de quem aprendeu que a dança pode compor, auxiliar a construir itinerários outros, provocando desvios para encontros com corpos e signos outros, e com a ausência daquilo que nada comunica e apenas nos informa. $\mathrm{O}$ gesto. Um gesto. Gestos.

Apresentaremos, a seguir, a motivação que nos levou a realizar a oficina "O que pode a Cartografia?"2 para, em seguida, apresentarmos as escutas que se deram por meio de uma conversa - noção contrabandeada por nós do epílogo escrito por Jorge Larrosa no livro “Pedagogia (improvável) da diferença e se o outro não estivesse aí?”, de Carlos Skliar (2003, p.213):

\footnotetext{
${ }^{2}$ Oficina realizada nos dias 20 e 21/10 e 25/11/2015, como parte das Atividades Programadas (AP), realizada junto ao Programa de Pós-Graduação em Educação da FAED/UDESC.
} 
[...] Nunca se sabe aonde uma conversa pode levar... uma conversa não é algo que se faça, mas algo no que se entra... e, ao entrar nela, pode-se ir aonde não havia sido previsto... e essa é a maravilha da conversa... que, nela, pode-se chegar a dizer o que não queria dizer, o que não sabia dizer, o que não podia dizer... $\mathrm{E}$, mais ainda, o valor de uma conversa não está no fato de que ao final se chegue ou não a um acordo... pelo contrário, uma conversa está cheia de diferenças e a arte da conversa consiste em sustentar a tensão entre as diferenças... mantendo-as e não as dissolvendo... e mantendo também as dúvidas, as perplexidades, as interrogações... e isso é o que a faz interessante... por isso, em uma conversa, não existe nunca a última palavra... por isso uma conversa pode manter as dúvidas até o final, porém cada vez mais precisas, mais elaboradas, mais inteligentes... por isso uma conversa pode manter as diferenças até o final, porém cada vez mais afinadas, mais sensíveis, mais conscientes de si mesmas... por isso uma conversa não termina, simplesmente se interrompe... e muda para outra coisa...

Portanto, as autoras e oficineiras, por meio de conversas e escutas, buscaram analisar, cartografar e dançar com as forças que atravessaram a produção dos mapas da sala de aula compostos pelos e nos participantes. Pistas das forças da cultura visual contemporânea, da cartografia escolar, da cartografia formal, das instituições de ensino superior, dos processos de subjetivação em curso com seus abalos e desabamentos, mesmo que ínfimos, apontaram possibilidades da ciência cartográfica também dançar e, ao dançar, mover-se entre as desobstruções, espaçamentos e esgarçamentos de suas linhas duras e, ao mesmo tempo, tênues. Linhas que sobraram do silenciamento deliberado das linguagens. Transtorná-las, quiçá. Transtorná-las para inventar uma dança, imperfeita e atravessada pelas cinzas que sobram dos incêndios.

\section{DAQUILO QUE FOI AGENCIADO}

Duas pesquisas em curso: uma intitulada "O que pode a cartografia e a geografia: investigações e invenções em educação" e a outra "Geografias em corpos". Nas duas é a cartografia que está em pauta. Por um lado a cartografia como qualidade de acompanhar os processos para que possamos dizer o que é preciso ser dito e, por outro, a cartografia da geografia, responsável por assegurar a produção de mapas ancorada na equivalência do espaço e sua representação que, de acordo com Massey (2008) refere-se aos "mapas normais ocidentais". Estes se constituem como imagens hegemônicas e sacralizadas acerca do espaço, permitindo-nos atribuir às instituições escolares e, por conseguinte, à geografia escolar, importâncias fulcrais no processo de uma política arquetípica sobre o espaço e sua representação. O cotidiano escolar trata-se de "uma região fronteiriça em que se manifestam concomitantemente práticas maioritárias em educação e expressões minoritárias de educação", cujos movimentos-conceitos engendram-se como processos que se coabitam ${ }^{3}$. (GALLO; FIGUEIREDO, 2015, p.26). Os dois movimentos-conceitos supracitados foram

\footnotetext{
3 "A ciência maior tem perpetuamente necessidade de uma inspiração que procede da menor; mas a ciência menor não seria nada se não afrontasse às mais altas exigências científicas, e se não passasse por elas". (DELEUZE; GUATTARI, 2012, p.208).
} 
forjados na esteira da obra "Mil Platôs", a partir das proposições maior e menor, das quais Deleuze e Guattari desenvolveram conceitos como ciência maior ou ciência sedentária, e ciência menor ou ciência nômade.

Do nosso encontro e do encontro das duas pesquisas elaboramos uma oficina oferecida na modalidade Atividade Programada para os alunos do Programa de PósGraduação em Educação da Universidade do Estado de Santa Catarina (UDESC). A fim de que nossas ideias de cartografia falassem fomos todos juntos cartografar a sala de aula onde o encontro acontecia. Em “O que pode a cartografia de uma sala de aula?" procuramos disparar meios de expressão para uma ideia.

O nosso propósito era fazer com que os/as estudantes mapeassem processos ligados a uma experimentação com a vida e o modo de fazer pesquisa no mundo contemporâneo. Os espaçamentos como possibilidade de criação pelos participantes, sem obliterar seus corpos, e quem sabe deslocá-los de contextos figurativos e representacionais asfixiantes da ciência maior. Apresentamos aos estudantes a pergunta supracitada, acrescentando que uma sala de aula (e os espaços) é atravessada por forças e interpelações que ultrapassam suas paredes fronteiriças e esquemas representacionais, ou seja, desejaríamos que as linhas desses afetos ser tocado, perturbado, contaminado - fossem cartografadas.

Para tanto, disponibilizamos ao grupo materiais diversos: retalhos de tecido com variadas texturas e cores; tesoura; tubo de cola; glitter; lápis de cor; giz de cera; revistas usadas; canetas hidrográficas; linhas e lãs; folhas A4, entre outros materiais. Consideramos esse conjunto de instrumentos do amplo repertório de materiais importantes, afinal, os próprios materiais (corpos sígnicos) ofertam possibilidades de abertura à invenção de outras maneiras de cartografar. Confeccionamos os mapas da sala de aula prestando atenção ao processo que os constituía. O começo foi difícil, mas todo começo parece ser assim meio paralisante, inebriante, demorado, arrastado. Não se sabe, de pronto, o que escolher, como compor, e onde vai se chegar. Ou como diz Luiz Tatit, na canção "O meio":

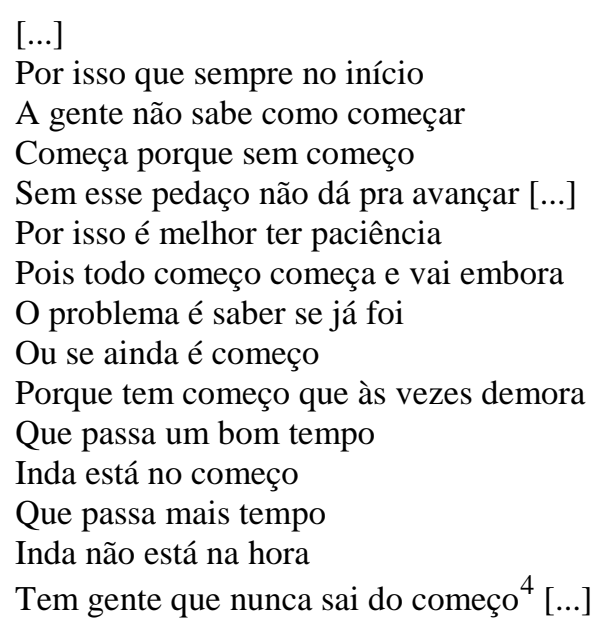

${ }^{4}$ Canção que nomeia o segundo disco solo de Luiz Tatit, lançado no ano 2000. Para maiores informações acessar: 〈http://goo.gl/5EqV4Y >. 
$\mathrm{Na}$ sala de aula organizamos as carteiras em círculo e no centro deixamos uma mesa repleta de materiais, mencionados anteriormente. Vários/as de nós tardamos para começar o mapa, mas começamos... pelo meio. "O meio é seguro pra gente cantar / Primeiro, acaba o bloqueio / E até o que era feio começa a soar / Depois todo aquele receio, sempre pelo meio" ". Pouco a pouco as linhas de força que atravessavam, ali, naquele momento, cada um/a de nós foram deslocadas para superfícies e texturas que não cabem nos mapas formais ou convencionais, mas estes podem ser rasgados, costurados e alinhavados a essas linhas de força para compor essas cartografias. Afinal, o que é uma sala de aula? Quais são seus planos? A hesitação do começo dizia respeito não só ao modo de trazer à tona uma cartografia, mas subjazia também uma questão: o que é uma sala de aula? O que é para dizer dela? O que é para fazer lá? Queríamos aquela sala de aula naquele momento. "Mas tudo tomou seu lugar", ou melhor dizendo, saiu de um lugar fixado pela imaginação espacial para desacostumar "os pontinhos pretos" dos mapas convencionais, pois "há possibilidade de haver tantas cartografias quanto sejam as geografias possíveis, mas para isso é preciso retomar - e reinventar - a linguagem cartográfica na coerência com o pensamento sobre o espaço" (GIRARDI, 2014, p.1-2).

\section{3 (DES)ACOSTUMAMENTOS I}

Após a elaboração dos mapas, prestamos atenção em cada um deles, conversando a respeito dos modos de fazer e sobre aquilo que disparou sua feitura. Nos dois excertos abaixo, as falas ${ }^{6}$ remetem para "equívocos" cometidos no mapa elaborado sobre a sala de aula e sobre a resposta errada para a questão feita, evidenciando um longo processo de subjetivação, tanto em relação à cultura geográfica escolar quanto à acadêmica, que operam com um repertório restrito e hegemônico no que se refere às noções de mapa e cartografia. É quase como se falassem: 'eu fiz errado'. Na figura 1, a seguir, o mapa foi confeccionado por uma pedagoga, utilizando recortes de linhas e tecidos coloridos colados numa folha A4, traços pretos feitos com caneta hidrocor representando as cadeiras dos alunos e outro tecido representando a cadeira da mesa do professor. Ao falar dos motivos que a levaram a fazer seu mapa, destacou: "Depois que vi os mapas de vocês - disse apontando para o mapa feito por uma de nós -, acho que o meu está errado. Eu não sabia que era pra fazer um mapa desse tipo. Optei pelo jeito convencional, me lembrando dos mapas que fazia nas aulas de geografia, dos mapas que estavam nas paredes das salas de aula, de todas elas. Percebi que o mapa de vocês ficou bem diferente do meu".

\footnotetext{
5 <http://goo.gl/1SEoDN>.

${ }^{6}$ Os trechos explicativos são oriundos de anotações em "diário de bordo", realizadas de memória logo após o término da oficina, que aconteceu nos dias 20 e 21/10 e 25/11/2015, como parte das Atividades Programadas (AP), realizadas junto ao Programa de Pós-Graduação em Educação da FAED/UDESC.
} 


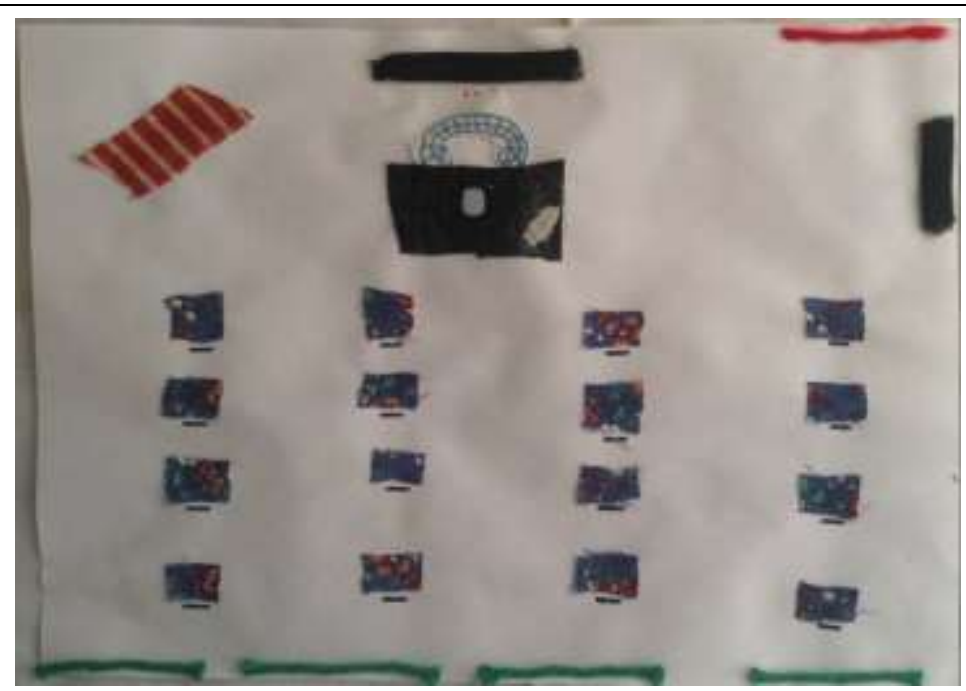

FIGURA 1

Fonte: Nosso acervo pessoal (2015)

Em uma folha à parte a estudante afirmou que "a proposta de cartografar a sala de aula naquele momento foi um pouco assustadora, pois não tenho conhecimento da área (área de conhecimento, quase nos dizendo: 'eu não sou geógrafa') e, portanto, não sabia o que deveria fazer. Nessa ânsia de acertar, acabei esboçando a sala de forma tradicional e não como ela estava de fato [...] Preocupei-me mais com a estética do que com a questão do conhecimento adquirido no processo da atividade". A aluna importou-se mais com produzir uma imagem do que seria um mapa, pois a sala de aula estava com as cadeiras dispostas em semicírculo e não enfileiradas, de modo que a figura 1 parece ser mais um clichê de sala de aula oriundo de uma subjetividade escolar do que propriamente um esforço de "representação". Para nós, nenhum problema, porque estávamos interessadas nos movimentos do grupo, nos passos que cada um inventava para produzir uma dança, para gerar seu mapa, afinal esse foi o movimento que nossa participante ensaiou na questão proposta: passos mais rígidos, imitando algumas imagens que nos acompanham. Ao concluir, olhou outros mapas ao seu lado e se pôs a pensar sobre o que havia feito, como havia feito e por que seu mapa possuía aquela feição.

Antes de elaborar a figura 2, o estudante-professor de História contou o número de carteiras e cadeiras, observando tanto a disposição do mobiliário daquela sala de aula como a localização da porta e janelas, persianas, lousa, armário, microcomputador, tela para data show. Em seguida recortou uma das bordas superiores de uma folha A4, procurando manter a proporção entre carteiras e outros equipamentos, formato e tamanho da sala de aula, e a maneira como havíamos disposto o mobiliário: "Quando vocês solicitaram que cartografássemos esta sala de aula, neste exato momento, não hesitei, e logo me pus a mapear a sala como um mapa convencional, ou seja, como se estivéssemos olhando lá de cima. Eu usei lápis de cor, régua e fiz vários pontos pretos para dar a sensação de rugosidade do piso." 


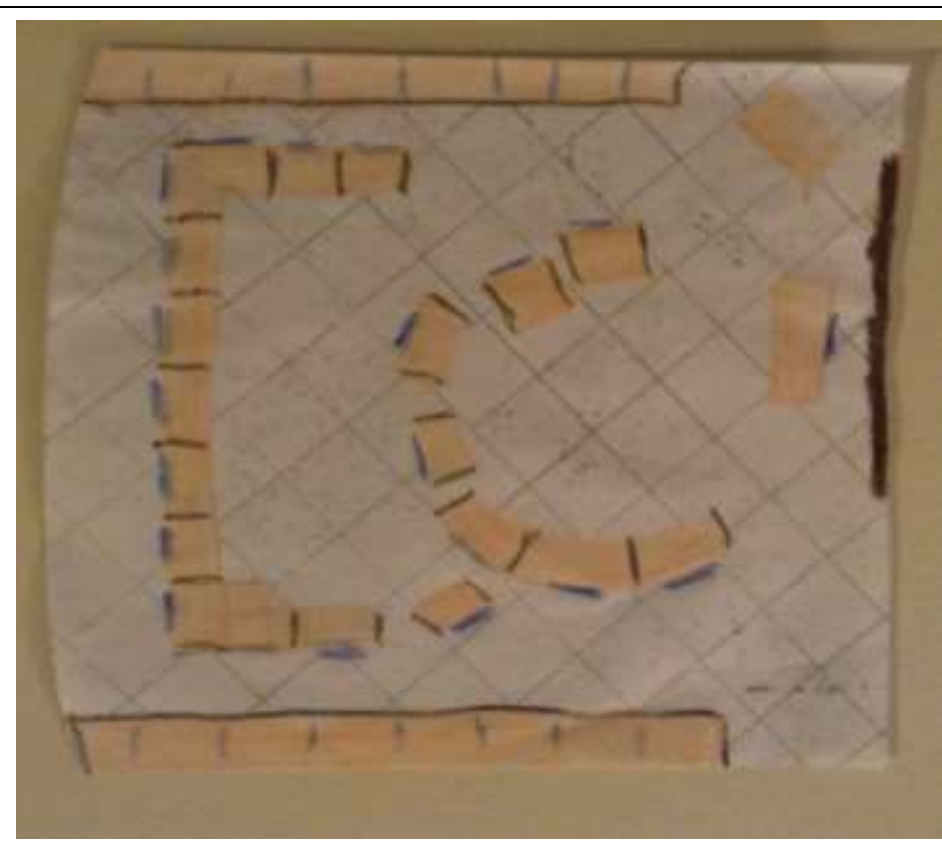

FIGURA 2

Fonte: Nosso acervo pessoal (2015)

Embora esses dois estudantes não tivessem formação específica em geografia, não hesitaram em cartografar a sala de aula e foram os primeiros a começar e terminar o mapa, mesmo considerando a proposta inusitada, afinal não tinham conhecimento específico da área. Isso nos faz pensar que:

a) está em curso, na contemporaneidade, um processo de subjetivação constituído de miradas lá do alto, legadas pelas linguagens tanto da Cartografia no registro representacional, como do Sensoriamento Remoto, seja em sua versão analógica com fotografias aéreas (verticais e oblíquas, em P\&B, coloridas, infravermelhas), seja em sua versão numérica por meio das imagens orbitais - empregadas em plataformas virtuais como o Google Earth -, seja no website do Google Maps. A prática de navegar em ambas tem nos educado a ratificar "que o espaço é uma superfície - que é a esfera de uma completa horizontalidade" (MASSEY, 2008, p.160), levando-nos a não perceber "as rupturas do espaço, o encontro com a diferença" (p.165).

b) para uma de nós, ao ter participado e acompanhado várias atividades durante o curso de licenciatura e de pós-graduação em geografia, pautadas na elaboração de mapas de sala de aula vistos de cima, como se estivéssemos sobrevoando um dado local, os dois mapas mencionados são bastante comuns nas práticas educativas de professores das séries iniciais e finais da disciplina escolar de geografia. No ensino superior, principalmente nos cursos de licenciaturas em geografia e de pedagogia, nas disciplinas voltadas para as metodologias de ensino de geografia ou em disciplinas como "Cartografia Escolar", recentemente criada, essa prática também é rotineira, reforçando "um pensamento da área de conhecimento" e conservando "os discursos dos saberes específicos” (PREVE e RECHIA, 2010, p.154). 


\section{4 (DES)ACOSTUMAMENTOS II}

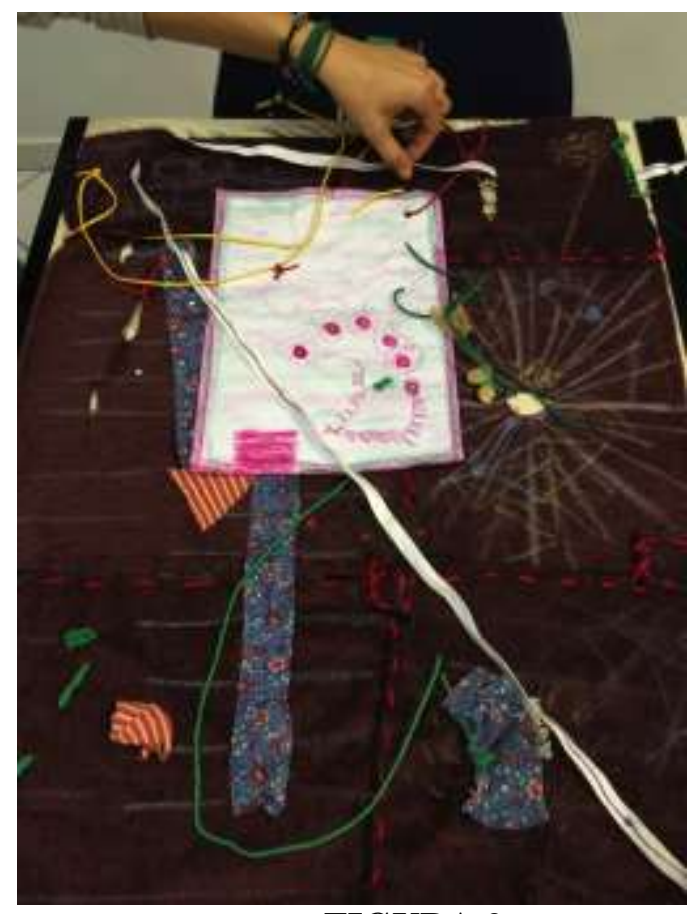

FIGURA 3

Fonte: Nosso acervo pessoal (2015)

"Foi difícil começar este mapa e a escolha dos materiais para elaborá-lo, simplesmente porque é muito difícil decidir um começo. É muito difícil apresentar graficamente essa sala de aula. Para mim é como se ela fosse um complexo composto de muitas atmosferas, de muitas tensões, de muitas imagens prontas, de muitos elementos materiais e não materiais. Tem o que a gente vê e todos outros planos que a gente não vê, mas que estão aí e funcionam, aliás, que fazem este lugar funcionar como sala de aula com suas regras, seus códigos, suas determinações do que pode e do que não pode. Uma sala de aula, para mim, é algo muito grande. Depois que iniciei, fui me conectando a um conjunto de forças. A partir daí criei espaçamentos, buracos, remendos e outros planos. Estou conectada a tudo isso por esta linha, amarrada no punho de meu braço esquerdo. Ao mesmo tempo que esta linha me libera, ela me prende. Estamos em um tempo-espaço em que a sala de aula, ao mesmo tempo me libera pra muita coisa, também me prende, como se ela fosse um sistema conectado a outros sistemas e dentro disso a gente ocupa um sistema que está pronto e é muito antigo. Quando digo que ela me libera é porque dentro disso posso imprimir outra velocidade".

O mapa da figura 3 foi elaborado com tecido em veludo, costurados com lã vermelha, folha A4, tiras de tecido e retalhos. Este mapa é "de uma ordem distinta dos produzidos pela Cartografia Científica, cujo foco concentra-se na superfície extensiva da Terra" (PREVE, 2010, p.18). A autora do mapa acima, professora universitária no curso de licenciatura em geografia, complementa: "este mapa não pode ser descolado dos processos que o ensejou. Se tirarmos dele esse caráter movente ele se desmancha, se desmonta. Aliás, esses mapas são frágeis, estão sempre se desfazendo e... se refazendo". 
A figura 4 constituída da colagem de duas folhas A4, sobre as quais foram colados pedaços de tecido, linha e glitter, apresenta os percursos de sua autora, também professora universitária, ancorados em linhas nas cores verde, vermelha e preta. "Essas linhas me ligam a territórios sobrevoados e aqueles que tenho percorrido corporalmente, na tentativa de escapar de alguns territórios mentais. Não basta viajar de avião, de carro, para escapar dos territórios que nos fixam como a raiz de uma planta. Entre o continente e a ilha ..." - e aponta para o tecido de cor preta, demarcando a cidade de São Paulo, e aquele colorido de branco e azul celeste, a ilha de Santa Catarina.

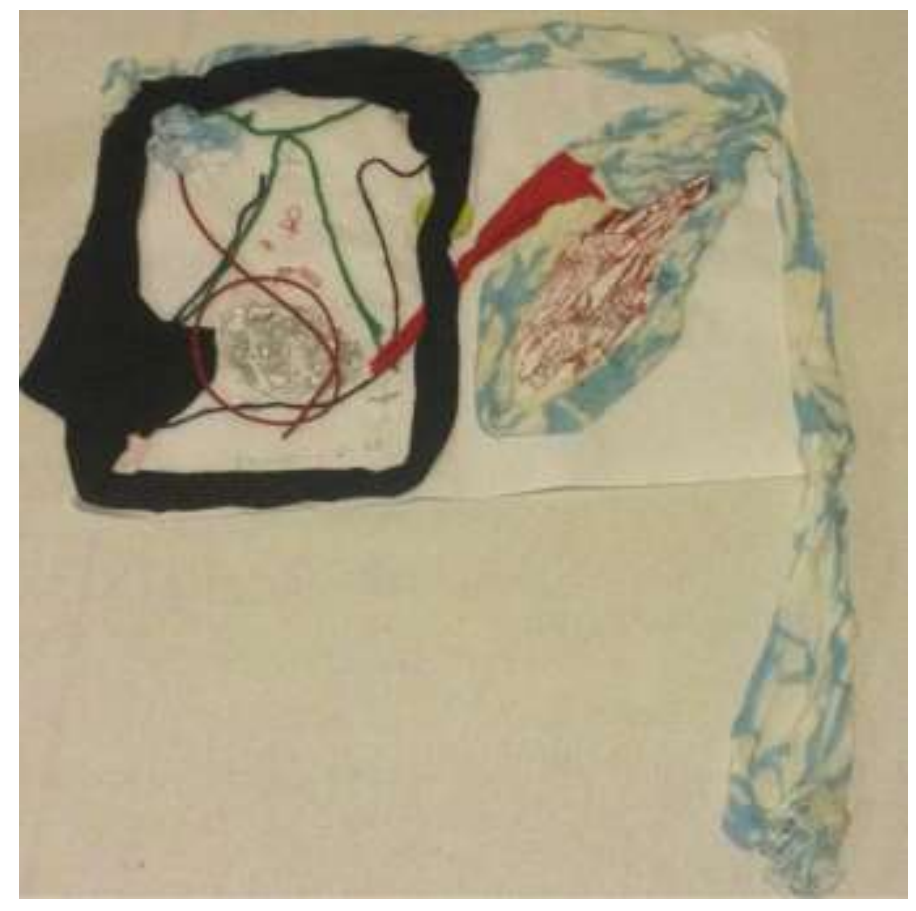

FIGURA 4

Fonte: Nosso acervo pessoal (2015)

A ilha, nesse mapa, está preenchida por glitter na cor vermelha, circundada por uma tira de tecido que sai dos limites da folha A4. "Meu mapa é de atravessamentos: estamos numa sala de aula, com todo repertório de lembranças fixadas em um jeito certo, inclusive, de produzir mapas. Neste mapa criei um continente, uma ilha e entre eles há percursos e imaginações que os conectam. Estou e estarei nestes fluxos...”.

Seu mapa ancora-se em duas folhas de papel A4. Não é fácil abandonar o papel e seus territórios fixos, nos quais nossas imaginações espaciais foram acostumadas a olhar e imaginar o espaço. Acostumamentos. E, de tão acostumada, segue com sua explicação geográfica apontando novamente para o mapa. "Essa ilha é continental. Uma ilha acidental, derivada do continente e, simultaneamente, desarticulada dele. Uma linha em fuga. Fugindo de quê?" Mas a extremidade de uma das pontas da tira de tecido branco e azul celeste sai da folha e a outra extremidade do tecido envolve o continente, a parte continental de Florianópolis, mas que também pode ser, segundo a autora do mapa, São Paulo. Duas 
capitais, São Paulo e Florianópolis, unidas por uma tira de tecido vermelho. Desacostumamentos.

"Não há razão alguma por ter escolhido a tira de tecido vermelho para unir o continente e a ilha. O tecido é como se fosse o desejo. O desejo, seja lá em relação ao que for, ajunta... territórios distantes na escala dos mapas da cartografia convencional, fazeres, pesquisas e amizades. Estou entre esses fluxos geográficos que estão propiciando mudanças... Este mapa evidencia processos em curso e, nesse sentido, se eu tivesse que cartografar esta sala de aula de novo, certamente, eu a faria de outro modo. Para além de todas as territorialidades da cidade de São Paulo há fluxos outros - enquanto falava apontava para o glitter de cor prata presente na sua composição - que brilham e fogem dessas tentativas de fechamento de nossas fronteiras".

A professora estaria se referindo a que tipo de fronteiras: as mentais? as políticas? as geográficas, que muitas pessoas são impedidas de ultrapassá-las corporalmente? Perguntas que ficaram sem respostas.

Os dois últimos mapas apresentam processos de pesquisa misturados aos processos de vida das duas autoras. No caso da figura 5, sua autora é professora na rede pública de ensino do Estado do Paraná e ela apresenta em seu mapa os processos em curso ao dar início ao mestrado acadêmico no Programa de Pós-Graduação em Educação da UDESC. O ponto de interrogação feito com massa de modelar amarela, por exemplo, diz respeito aos desafios e questões que surgirão ao longo de sua pesquisa sobre oficinas abordando sexualidade e diversidade sexual. "A linha de tecido verde tracejada no meu mapa indica trajetos que realizo para além desta sala de aula. O 'coffe' (sic) é porque frequento bastante a cantina da FAED, onde converso com meus colegas de turma do mestrado. Trata-se de um espaço muito importante para mim".

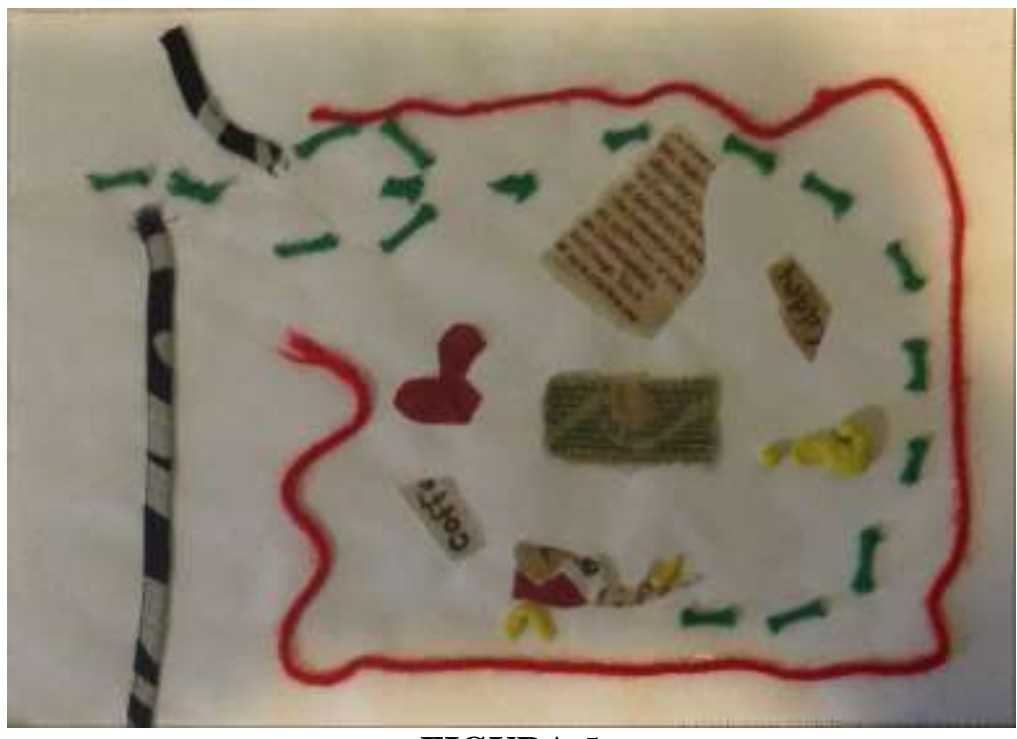

FIGURA 5

Fonte: Nosso acervo pessoal (2015) 
A autora da figura 6, a seguir, também professora universitária no curso de geografia, o mapa como estando sempre aberto. Os dois círculos, na parte superior da folha, indicam as professoras ministrantes da oficina e o outro círculo seriam os alunos conectados às professoras por uma linha verde que, por sua vez, liga-se a uma linha vermelha na qual está pendurado uma espécie de embornal. "Elaborei meu mapa a partir daquilo que está me atravessando nessa oficina como a dificuldade em lidar com a cartografia do Deleuze e do Guattari. Eu preciso da outra cartografia também, daquela mais convencional. Essa outra noção de cartografia, como processo, é bastante interessante também. Eu coloquei escala no meu mapa, escala de quantas pessoas participaram da oficina, e inseri também o número da sala de aula onde estamos".

Ao perguntarmos a ela porque escreveu em seu mapa "simbologia/discurso confuso ou cartográfico" afirmou-nos: "não há um jeito único de lidar com a cartografia dessa perspectiva que vocês lidam e, às vezes, isso me deixa confusa. As imagens aqui podem ser mapas".

Interessante a afirmação da professora porque parece que vale tudo nessa acepção da cartografia. No registro deleuziano-guattariano, no entanto, se obliterarmos as forças dos processos que nos levam a produzir esses mapas, eles se desmancham, se desfazem. Não há nada da ordem do intempestivo que seja passível de ser representado. Por isso as narrativas produzidas junto da elaboração desses mapas são uma parte dos processos concernente às linhas de força que nos movem e nos conectam à criação de outros espaços, quiçá mais desconectados da codificação aprisionante da linguagem.
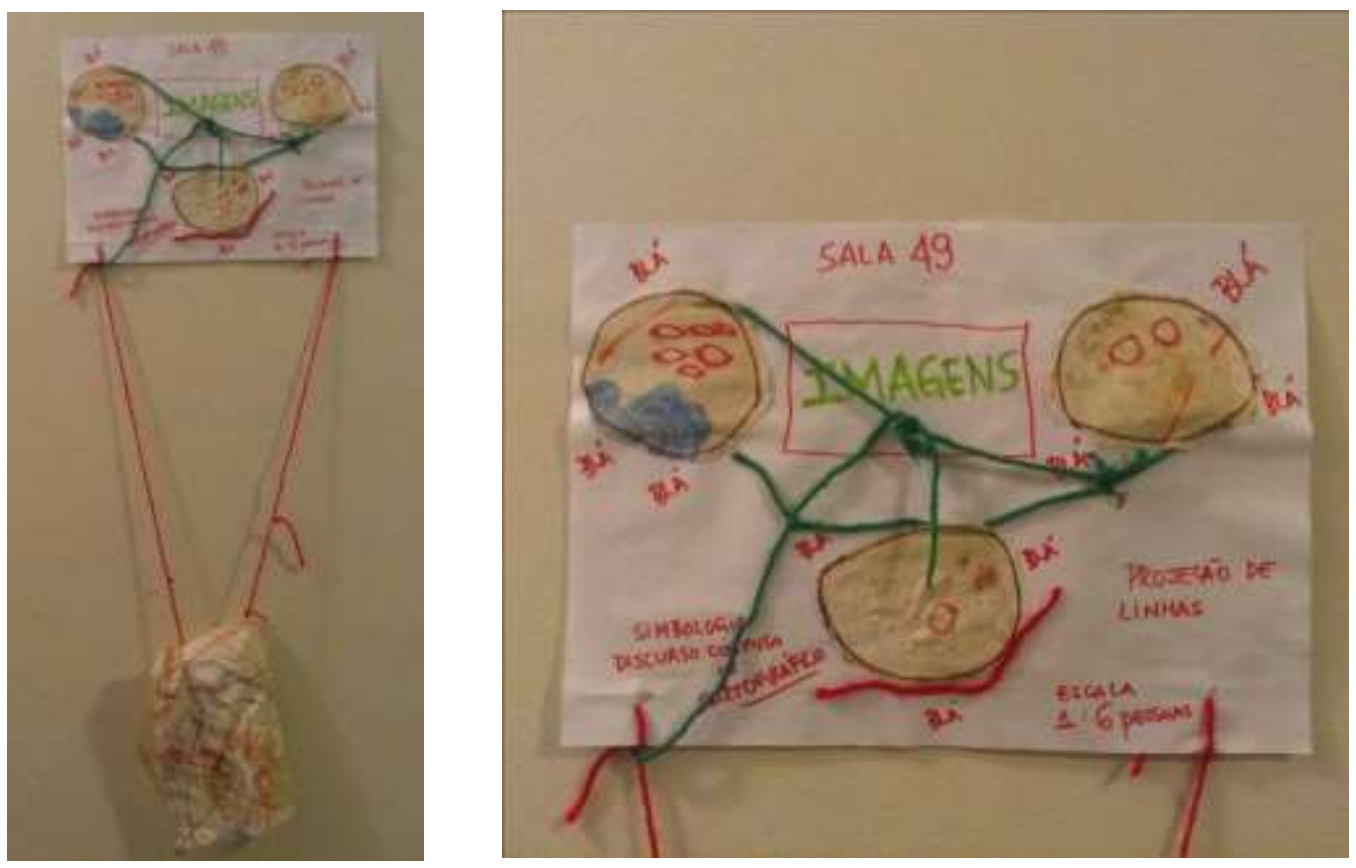

FIGURA 6

Fonte: Nosso acervo pessoal (2015) 


\title{
5 CONSIDERAÇÕES FINAIS DE ALGUMAS MOVÊNCIAS
}

As cartografias elaboradas da sala de aula, isto é, o processo da oficina incluindo a conversa das autoras/oficineiras com as/os participantes, somente fizeram sentido nessa acepção rizomática porque perturbaram, de algum modo, o repertório que temos acerca das noções de mapa e cartografia oriundas da educação visual mais ampla tanto quanto da cultura geográfica escolar e acadêmica, cuja primazia insiste em uma versão da cartografia como arquétipo de mapas. Essas cartografias não foram produzidas de modo generalista, representativo ou extensivo. Suas urdiduras decorreram tanto das rugosidades dos materiais empregados por cada um/a deles/as quanto das forças agenciadas no contexto da oficina.

Neste texto, ao abordarmos a oficina e sua escuta por meio da produção de cartografias de uma sala de aula, partilhamos da ideia de Masschelein (2008) acerca do ato de educar como sinônimo de um convite a caminhar, a experimentar. Ao caminhar podemos experimentar ações que não estão em nossos repertórios costumeiros e linguageiros e, ao experimentarmos, podemos entrar em contato com outros caminhos ainda não pisados por nossos pés. Caminhar para experimentar uma pedagogia pobre, pois esta nos

\begin{abstract}
oferece meios para experimentarmos (ao invés de fornecer explicações, interpretações, justificativas, representações, histórias, critérios, etc.) meios para que nos tornemos atentos. Esses meios são pobres, insuficientes, defeituosos, carentes de significado, não se referem a um objetivo ou fim, meios puro, pistas que não levam a lugar algum, e que, por isso mesmo, podem levar a todos os lugares [...] .(MASSCHELEIN, 2008, p.43)
\end{abstract}

Propor algo em educação passa por desacostumar discursos textuais e visuais por meio do caminhar-experimentar, mesmo que isso expresse mudanças em movimentos sutis "quando olhamos alguma coisa diferentemente do que vínhamos fazendo até então" (PREVE e RECHIA, 2010, p.160). Movimentos, portanto, de cartografias dançarinas. Eis os mapas produzidos, cujas linhas oscilam entre um jeito de fazer contaminado pela educação visual dos pontos de vista dos mapas e das imagens vistas de cima, e uma experiência "assustadora" (nas palavras de uma estudante), perturbadora "que, ao mesmo tempo, me libera pra muita coisa, também me prende", conforme mencionou uma das participantes.

Ao lidarmos com as noções de mapa e cartografia nosso intuito foi operacionalizá-los em uma oficina sobre o que pode a cartografia de uma sala aula para fazer dançar as linhas duras que compõem nossos mundos, uma sala de aula, no caso desse texto, e a nós mesmos. Com esses passos tímidos, auxiliados por nós e pelo conjunto de textos que elegemos na organização da Atividade Programada, chegamos mais perto para um começo de conversa sobre mapas, cartografias e uma urgência para afrouxar as linhas duras com que se pretende representar o espaço, a vida, o mundo, uma sala de aula. Não dançamos, mas com certeza sentimos a necessidade de movimentar o corpo e o pensamento para depois talvez dançar e cartografar estas linhas invisíveis 
como quem constrói sua terra natal, por mais imaterial que ela seja, a partir da qual certos processos de subjetivação podem desdobrar-se e ganhar consistência [...] uma camada intensiva, que tem a ver com as imagens mas não deriva delas, que tem a ver com a linguagem mas não deriva dela. (PELBART, 1993, p. 53)

O trabalho aqui apresentado fez alguma coisa se passar, e o que se passa é também um devir louco de algumas linhas cartografadas no decorrer da oficina, permitindo outros possíveis na maneira como se pensa o espaço. Um devir louco que arrasta participantes, arrasta a geografia, a educação e que pode aflorar a qualquer tempo em qualquer canto, dissolvendo os nomes gerais e o saber que eles carregam: as palavras e as linhas se movimentam enlouquecidas não mais designando sujeitos, antes perdendo a capacidade de se fixarem como referências. Instala-se aí uma movência, uma dança, e por meio dela abandonam-se os caminhos já traçados, as verdades derradeiras escapando ao presente que fixa e ao espaço que se divide em partes.

Outras atividades programadas seguiram-se a esta, tomadas pelos primeiros passos alçados nesta oficina. O que parece pouco, não é. O que nos sobra são as cinzas da oficina realizada pelo transtornar hábitos cartográficos. As cinzas são aquilo que sobrou de uma dança espacial sem interrupção, cujas linhas de fuga, por mais raras que sejam, podem se aquecer novamente sem nos apresentar garantia alguma sobre a invenção de espaçamentos e territórios existenciais nos quais suas dobras, ou seja, aquilo que não foi cartografado por algum tipo de linguagem, tenha a chance de se efetuar no mundo como um saber que escape aos saberes constituídos, saber livre das amarras da linguagem escolar. O que tentamos foi criar "vacúolos de não-comunicação" (DELEUZE, 2013, p.221), alguns interruptores, para escapar aos esquemas de controle do que se diz e do como se diz sobre o espaço, mesmo que por alguns instantes. A força deste trabalho está muito mais para o deslocamento que provocou em seus participantes no que diz respeito ao modo como se pensa o espaço a partir de uma linguagem cartográfica que povoa os esquemas escolares: um acontecimento de superfície ou volume reduzido com potências de fuga ao controle de um tipo de informação espacial (DELEUZE, 2013). 


\section{REFERÊNCIAS}

ALBUQUERQUE JÚNIOR, Durval Muniz. A invenção do Nordeste e outras artes. 5. ed. São Paulo: Cortez, 2011.

ALVAREZ, Johnny; PASSOS, Eduardo. Pista 7. Cartografar é habitar um território existencial. In: PASSOS, Eduardo; KASTRUP, Virgínia; ESCÓSSIA, Liliana da. (Orgs.). Pistas do método da cartografia: pesquisa-intervenção e produção de subjetividade. Porto Alegre: Sulina, 2009, p. 131-149. Disponível em: 〈http://goo.gl/t6muUa >. Acesso em: 07 set. 2016.

DELEUZE, Gilles; GUATTARI, Félix. 1. Introdução: Rizoma. In: DELEUZE, Gilles; GUATTARI, Félix. Mil Platôs: capitalismo e esquizofrenia. Tradução de Ana Lúcia de Oliveira, Aurélio Guerra Neto e Celia Pinto Costa. São Paulo: Editora 34, 1995. v.1. p. 17-50. Disponível em: 〈http://goo.gl/jPCG2o >. Acesso em: 07 set. 2016.

DELEUZE, Gilles; GUATTARI, Félix. Mil platôs: capitalismo e esquizofrenia. Tradução de Peter Pál Pelbart e Janice Caiafa. 2. ed. São Paulo: Editora 34, 2012. v. 5. Disponível em: <http://goo.gl/6QjnJd>. Acesso em: 07 set. 2016.

DELEUZE, Gilles. Conversações. 3. ed. Tradução de Peter Pál Pelbart. Rio de Janeiro, Editora 34, 2013. Disponível em: 〈http://goo.gl/2Nj5wA〉. Acesso em: 07 set. 2016.

DIDI-HUBERMAN, Georges. Diante da imagem: questão colocada aos fins de uma história da arte. Tradução de Paulo Neves. São Paulo: Editora 34, 2013. Disponível em: <http://goo.gl/1FbgfA >. Acesso em: 07 set. 2016.

GALLO, Sílvio; FIGUEIREDO, Gláucia Maria. Entre maioridade e menoridade: as regiões de fronteira no cotidiano escolar. Aprender - Caderno de Filosofia e Psicologia da Educação, Vitória da Conquista, BA, v. 09, n. 14, p. 25-51. 2015. Disponível em: <http://goo.gl/iupngX>. Acesso em: 10 out. 2016. ISSN 1678-7846.

GIRARDI, Gisele. Entre obras de arte e cartografia geográfica: intercessores. In: COLÓQUIO IBÉRICO DE GEOGRAFIA, 4., 2014, Guimarães. Anais eletrônicos... APG/UMinho, 2014. v. 1. p. 488-493. Disponível em: 〈http://goo.gl/SfCKlh〉. Acesso em: 07 set. 2016.

KASTRUP, Vírginia. Pista 2. O funcionamento da atenção no trabalho do cartógrafo. In: PASSOS, Eduardo; KASTRUP, Virgínia; ESCÓSSIA, Liliana da. (Orgs.). Pistas do método da cartografia: pesquisa-intervenção e produção de subjetividade. Porto Alegre: Sulina, 2009. p. 32-51. Disponível em: 〈http://goo.gl/t6muUa >. Acesso em: 07 set. 2016.

KASTRUP, Virgínia; PASSOS, Eduardo. Pista do comum. Cartografar é traçar um plano comum. In: PASSOS, Eduardo; KASTRUP, Virgínia; TEDESCO, Silvia. (Orgs.). Pistas do método da cartografia: a experiência da pesquisa e o plano comum. Porto Alegre: Sulina, 2014. p. 15-41. Disponível em: 〈http://goo.gl/a9vWxe〉. Acesso em: 07 set. 2016. 
LARROSA, Jorge. A arte da conversa. In: SKLIAR, Carlos. Pedagogia (improvável) da diferença e se o outro não estivesse aí? Tradução de Giane Lessa. Rio de Janeiro: DP\&A, 2003. p. 211-216.

MASSCHELEIN, Jan. E-ducando o olhar: a necessidade de uma pedagogia pobre. Educação e Realidade, Porto Alegre, RS, v. 33, n. 01, p. 35-48. 2008. Disponível em 〈http://goo.gl/RXDrLF>. Acesso em: 05 mar. 2016. ISSN 2175-6236.

MASSEY, Doreen. Pelo espaço: uma nova política da espacialidade. Tradução de Hilda Pareto Maciel e Rogério Haesbaert. Rio de Janeiro: Bertrand Brasil, 2008. 312 p.

NOVEMBER, Valérie; CAMACHO-HÜBNER, Eduardo; LATOUR, Bruno. Entrando em território arriscado. Terra Brasilis, n. 02, p. 01-26. 2013. Disponível em: <http://goo.gl/PTiAvd >. Acesso em: 12 fev. 2016.

PELBART, Peter Pál. Ecologia do invisível. In: PERBART, Peter Pál. A nau do tempo rei: sete ensaios sobre o tempo da loucura. Rio de Janeiro: Imago, 1993. p. 48-61. Disponível em: <http://goo.gl/Y0XBeC>. Acesso em: 07 set. 2016.

PREVE, Ana Maria Hoepers. Mapas, prisão e fugas: cartografias intensivas em educação. 2010. 347 f. Tese (Doutorado em Educação) - Faculdade de Educação, Universidade Estadual de Campinas, Campinas, SP, 2010. Disponível em: 〈http://goo.gl/3bKvd1 >. Acesso em: 07 set. 2016.

PREVE, Ana Maria Hoepers; RECHIA, Karen Christine. Outros mundos: perversão no planisfério político. ETD - Educação Temática Digital, Campinas, SP, v. 11, n. 02, p.146164. jan./jun. 2010. Disponível em: 〈http://goo.gl/XvL7bh>. Acesso em: 10 mai. 2016. ISSN: $1676-2592$.

SKLIAR, Carlos. Pedagogia (Improvável) da Diferença: e se o outro não estivesse aí? Rio de Janeiro: DP\&A, 2003. 312 p.

SZYMBORSKA, Wislawa. Mapa e outros três poemas. Tradução de Regina Przybycien. Folha de S. Paulo, São Paulo, SP, Ilustríssima, 27 jan. 2013. Disponível em: 〈http://goo.gl/cmHXLR>. Acesso em 10 jan. 2016. 


\section{VALÉRIA CAZETTA}

Doutora em Geografia (Organização do Espaço) Universidade Estadual Paulista "Júlio de Mesquita Filho" - UNESP Rio Claro, SP - Brasil Professora Doutora da Universidade de São Paulo - USP São Paulo, SP - Brasil E-mail: vcazetta@gmail.com

ANA MARIA HOEPERS PREVE Doutora em Educação Universidade Estadual de Campinas - UNICAMP Campinas, SP - Brasil

Professora Adjunta Universidade do Estado de Santa Catarina - UDESC Florianópolis, SC - Brasil E-mail: anamariapreve@gmail.com

Recebido em: 07/09/2016 Aprovado para publicação em: 09/10//2016

Como citar este documento:

CAZETTA, Valéria; PREVE, Ana Maria Hoepers. Uma Cartografia que pode dançar. ETD - Educação Temática Digital, Campinas, SP, v. 18, n. 4, p. 857-874, nov. 2016. ISSN 1676-2592. Disponível em: <http://periodicos.sbu.unicamp.br/ojs/index.php/etd/article/view/8646438>. Acesso em: 16 nov. 2016. doi:http://dx.doi.org/10.20396/etd.v18i4.8646438. 